\title{
Evaluation of electrocardiographic ventricular and atrial repolarization markers in patients with high grade varicocele
}

\author{
Emrah Erdal $^{1}$, Isa Sincer ${ }^{1}$, Mehmet Inanir ${ }^{1}$, Adnan Gucuk ${ }^{2}$, Yilmaz Gunes ${ }^{1}$, Emre Bostanci $^{2}$ \\ ${ }^{I}$ Department of Cardiology, Bolu Abant Izzet Baysal University, Faculty of Medicine, Bolu, Turkey \\ ${ }^{2}$ Department of Urology, Bolu Abant Izzet Baysal University, Faculty of Medicine, Bolu, Turkey
}

\section{ABSTRACT}

\begin{abstract}
Aim: Varicocele is abnormal dilation of testis veins without unclear pathophysiology. Morphological studies showed imbalance between vasoconstrictor and vasodilator mechanisms. We aimed to determine the relationship between varicocele and cardiovascular system disorders with electrocardiography (ECG) parameters.
\end{abstract}

Methods: This is a prospective study which was conducted in a University Hospital between February and June 2018. Thirty patients (18-45 years old) with high grade varicocele from urology outpatient clinic and 32 healthy volunteers for the control group were recruited to the study.

Results: P-min. value was significantly higher in control group than patients with high grade varicocele $(\mathrm{p}=0.03)$. PR, QT and QTc intervals, PWD and P-max values were similar. Also, there were no significant differences in terms of the other ECG parameters between the groups.

Conclusions: In this small prospective study we have found no association between high grade varicocele and potential electrocardiographic arrhythmia predictors namely OTd, QTc interval, PWD, $\mathrm{Tp}$-e interval, Tp-e/QT ratio and Tp-e/QTc ratio. Long-term follow-up and large-scale prospective studies are needed to confirm our results.

Keywords: Arrhythmias, high grade varicocele, P-wave dispersion, QT dispersion, Tp-e/QTc ratio.

Copyright $₫ 2019$ experimentalbiomedicalresearch.com

Corresponding Author:

Dr. Emrah Erdal

Department of Cardiology, Bolu Abant Izzet Baysal

University, Faculty of Medicine, Bolu, Turkey

Email:dr.emraherdal@gmail.com

ORCID ID: https://orcid.org/0000-0002-3893-5376

Received 2018-12-24,

Accepted 2019-01-26,

Publication Date 2019-03-14
Introduction

Varicocele is abnormal dilation of testis veins [1]. The prevalence of varicocele is estimated to be $15-22 \%$ in the adult population $[2,3]$. Varicocele is seen in $30-40 \%$ of patients with male infertility $[4,5]$.

The pathophysiology of varicocele is still unclear. Some morphological studies have shown imbalance between vasoconstrictor and vasodilator mechanisms. Increased 
vasoconstrictor activity and endothelial dysfunction has been demonstrated especially in high-grade varicoceles $[6,7]$. An association between varicocele and lower extremity venous insufficiency has been reported in several studies [8-10]. Also, correlation between coronary artery ectasia and varicocele has been documented $[11,12]$. These findings suggest that varicocele may be associated with diffuse vascular abnormality as a part of systemic disease.

Increased dispersion of repolarization and electrical instability may cause ventricular arrhythmias and sudden cardiac death [13, 14]. Myocardial repolarization can be assessed with QT interval (QT), corrected QT interval (QTc), QT dispersion (QTd), T-wave peak to the end interval (Tp-e) Tp-e/QT and Tp-e/QTc ratios. Furthermore, P-wave dispersion (PWD) has been advocated as a measurement of the heterogeneity of atrial depolarization, which may be useful for the assessment of atrial fibrillation (AF) risk [15].

As far as we know there is no study about relationship between high grade varicocele and cardiac arrhythmias. In this study, we aimed to search the relationship between high-grade varicocele and potential electrocardiographic (ECG) arrhythmia markers; QTd, QTc, Tp-e interval, Tp-e/QT ratio, Tp-e/QTc ratio and PWD.

\section{Methods}

\section{Study population}

This is a prospective study conducted at Bolu Abant Izzet Baysal University Hospital between February 2018 and June 2018. The study protocol was approved by Bolu Abant Izzet Baysal University Clinical Research Ethics Committee (2018/38) and a written informed consent was obtained from each subject. All procedures performed in studies involving human participants were in accordance with the ethical standards of the institutional and/or national research committee and with the 1964 Helsinki declaration and its later amendments or comparable ethical standards.

Thirty patients (18-45 years old) with highgrade varicocele attending urology outpatient clinic and 32 healthy volunteers as a control group were recruited to the study.

High-grade varicocele (grade 3 ) was diagnosed with scrotal color Doppler ultrasound. Reflux with Valsalva maneuver longer than one second which is independent of vessel diameter was determined as grade 3 varicocele [16].

All participants were underwent transthoracic echocardiographic examination and patients with heart failure, valvular heart diseases or cardiomyopathy and patients with a systemic disease like hypertension, diabetes mellitus, coronary artery disease, peripheral artery disease, arrhythmia, thyroid disorder, collagen tissue disease or malignancies were excluded. The patients getting any drug due to common cold or any other reason were also not included.

\section{Electrocardiography}

Twelve-lead ECGs were obtained after a 10minute rest, with $10 \mathrm{~mm} / \mathrm{mV}$ amplitude and 25 $\mathrm{mm} / \mathrm{s}$ rate with standard lead positions in a supine position using commercially available machine (Nihon Kohden Cardiofax ECG1950 VET). ECGs were manually measured with a magnifying glass (TorQ $150 \mathrm{~mm}$ Digital Caliper LCD) by two blinded cardiologists having no information about subjects. The difference between maximum and minimum Pwave duration was defined as PWD. QT intervals were measured beginning from the 
onset of the QRS complex to the end of the T wave. The R-R interval was measured and used to compute the heart rate and QTc with Bazett's formula [17].

QT dispersion was determined as the difference between the maximum and minimum QT interval in different leads. The Tp-e interval was defined from the peak of $T$ wave to the end of $\mathrm{T}$ wave from precordial leads [18]. Tp-e/QT and Tp-e/QTc ratios were calculated. The intra-observer and interobserver variations for measurements were less than $10 \%$.

\section{Statistical analysis}

SPSS 15.0 Statistical Package Program for Windows (SPSS Inc, Chicago, Illinois, USA) was used for analysis. Quantitative variables are expressed as mean \pm standard deviation (SD) and qualitative variables as numbers and percentages. Differences between independent groups were assessed by $t$-tests for quantitative data and Chi-square test for qualitative variables and with Mann-Whitney's U test for variables without normal distribution. A twotailed $\mathrm{P}$ value of $<0.05$ was considered significant.

\section{Results}

Demographic characteristics of participants were similar (Table 1). Electrocardiographic measurements of patients with high-grade varicocele and healthy control group were presented in Table 2. P-min value was significantly higher in control group than patients with high-grade varicocele $(p=0.03)$. However, PR, QT and QTc intervals, PWD and $\mathrm{P}$-max values were similar. There were no significant differences in terms of the other ECG parameters (Tp-e interval, Tp-e/QT ratio and Tp-e/QTc ratio) between the groups.
Table 1. General characteristics of the study groups.

\begin{tabular}{|l|l|l|l|}
\hline $\begin{array}{l}\text { Baseline } \\
\text { characteristics }\end{array}$ & $\begin{array}{l}\text { Control } \\
(\mathrm{n}=32)\end{array}$ & $\begin{array}{l}\text { Varicocele } \\
(\mathrm{n}=30)\end{array}$ & $p$ \\
\hline $\begin{array}{l}\text { Age (mean } \pm \text { SD) } \\
\text { (years) }\end{array}$ & $\mathbf{2 6 \pm 6}$ & $27 \pm 7$ & $\mathbf{0 . 6 0 2}$ \\
\hline $\begin{array}{l}\text { Body mass index } \\
(\mathrm{kg} / \mathrm{m} 2)\end{array}$ & $22 \pm 3$ & $\mathbf{2 4} \pm 3.5$ & $\mathbf{0 . 0 5 4}$ \\
\hline Smoking & $10(31 \%)$ & $10(33 \%)$ & $\mathbf{0 . 8 6 1}$ \\
\hline
\end{tabular}

SD: Standard deviation

Table 2. Electrocardiographic measurements of patients with high-grade varicocele and healthy control group.

\begin{tabular}{|l|l|l|l|}
\hline Parameters & $\begin{array}{l}\text { Control } \\
(\mathbf{n}=\mathbf{3 2})\end{array}$ & $\begin{array}{l}\text { Varicocele } \\
(\mathbf{n}=\mathbf{3 0})\end{array}$ & $p$ \\
\hline P-max.(ms ) & $105.2 \pm 10.7$ & $101.9 \pm 9.1$ & 0.208 \\
\hline P-min.(ms ) & $82.8 \pm 10.2$ & $77.8 \pm 7.3$ & $\mathbf{0 . 0 3}$ \\
\hline PR duration (ms) & $151.2 \pm 17.1$ & $147.3 \pm 16.2$ & 0.356 \\
\hline QRS duration (ms ) & $90.7 \pm 8.1$ & $93.8 \pm 8.9$ & 0.175 \\
\hline Heart rate (bpm ) & $70.1 \pm 11.5$ & $74.1 \pm 13.2$ & 0.324 \\
\hline QTc (ms ) & $388.2 \pm 19.0$ & $396.7 \pm 21.6$ & 0.106 \\
\hline QT max. ( ms ) & $373.4 \pm 27.3$ & $370.7 \pm 20.6$ & 0.67 \\
\hline QT min. ( ms ) & $351.2 \pm 28.1$ & $348.4 \pm 20.8$ & 0.66 \\
\hline Tp-e (ms ) & $79.1 \pm 10.2$ & $77.1 \pm 8.9$ & 0.408 \\
\hline cQTd (ms ) & $23.9 \pm 9.9$ & $24.5 \pm 8.4$ & 0.78 \\
\hline PWD ( ms ) & $22.3 \pm 7.3$ & $24.2 \pm 7.6$ & 0.337 \\
\hline QTd (ms ) & $22.1 \pm 8.6$ & $22.3 \pm 6.8$ & 0.94 \\
\hline Tp-e/QTc & $0.204 \pm 0.029$ & $0.194 \pm 0.021$ & 0.137 \\
\hline QT (ms ) & $548.9 \pm 40.9$ & $544.9 \pm 30.7$ & 0.663 \\
\hline Tp-e/QT & $0.144 \pm 0.021$ & $0.141 \pm 0.017$ & 0.552 \\
\hline
\end{tabular}

cQTd : corrected QT dispersion, bpm: beat per minute, ms: millisecond, PWD: P-wave dispersion, QTc: corrected QT, QTd: QT dispersion

\section{Discussion}

In this study, we found that ECG parameters including PWD, QTd and Tp-e interval were 
not significantly different in patients having high-grade varicoceles.

Varicocele remains a controversial disease, which is a common cause of male infertility. Correlations between varicocele and coronary artery ectasia and peripheral venous insufficiency have been shown in several studies [10, 19]. Inflammatory pathogenesis has been reported to play a role in both coronary artery ectasia and peripheral varicose veins [20]. Nitric oxide (NO) has been reported to a have a role both on varicocele pathophysiology and cardiovascular diseases. It acts as a vasodilator in the circulatory system and prevents endothelial dysfunction [21]. Accordingly, some studies have suggested that varicocele is part of a systemic inflammation and diffuse vascular disease [22].

Systemic inflammation might have a substantial impact on arrhythmogenesis through a variety of direct and indirect triggers [23]. The increase of ventricular repolarization dispersion is associated with malignant arrhythmias and has prognostic importance in terms of mortality and sudden cardiac death [24]. QTd is an important ECG parameter, which may predict ventricular arrhythmia, sudden death and other cardiac events [13, 25]. Tp-e interval is an ECG parameter related to ventricular arrhythmogenesis and repolarization heterogeneity [14]. Some studies have shown that prolongation of the Tp-e interval is related to ventricular arrhythmias [18,26]. PWD is an ECG parameter used to evaluate intra-atrial and inter-atrial conduction times and is useful for determining the risk of developing atrial fibrillation $[27,28]$.

In our study, there were no differences between high-grade varicocele patients and healthy subjects in respect to possible electrocardiographic predictors of arrhythmias. Similarly, Kilic et al. [12] have reported that varicocele was not associated with cardiovascular risk factors and demographic parameters in their study.

To the best of our knowledge, this is the first study to evaluate the effect of high grade varicocele on myocardial and atrial repolarization dispersion determined by QTd, Tp-e interval and PWD. In this study, we found that there were no significant differences between high grade varicocele and healthy subjects in respect to QT interval, Tp-e interval, Tp-e/QT and Tp-e/QTc ratio. Also, PWD were similar in both groups.

\section{Conclusions}

In this small prospective study, we have found no association between high-grade varicocele and potential electrocardiographic arrhythmia predictors namely OTd, QTc interval, PWD, Tp-e interval, Tp-e/QT ratio and Tp-e/QTc ratio. Long-term follow-up and large-scale prospective studies are needed to confirm our results.

Conflict of Interest: No conflict of interest was declared by the authors.

Funding sources: None

Informed Consent: Written informed consent was obtained from the patients who participated in this study.

\section{References}

[1]Nöske HD, Weidner W. Varicocele--a historical perspective. World J Urol. 1999; 17(3):151-57.

[2]Akbay E, Cayan S, Doruk E, Duce MN, Bozlu M. The prevalence of varicocele and varicocele-related testicular atrophy in Turkish children and adolescents. BJU Int. 2000; 86(4):490-93. 
[3]Kursh ED. What is the incidence of varicocele in a fertile population? Fertil Steril. 1987; 48(3):510-11.

[4]Hendry WF, Sommerville IF, Hall RR, Pugh RC. Investigation and treatment ofthe subfertile male. Br J Urol. 1973; 45(6):68492.

[5]Cockett AT, Takihara H, Cosentino MJ. The varicocele. Fertil Steril. 1984; 41(1):511.

[6]Yildiz O, Gul H, Ozgok Y, Onguru O, Kilciler M, Aydin A, et al. AC. Increased vasoconstrictor reactivity and decreased endothelial function in high grade varicocele; functional and morphological study. Urol Res. 2003; 31(5):323-28.

[7]Terquem A, Dadoune JP. Morphological findings in varicocele: an ultrastructural study of 30 bilateral testicular biopsies. Int J Androl. 1981; 4(5):515-31.

[8]Koyuncu H, Ergenoglu M, Yencilek F, Gulcan N, Tasdelen N, Yencilek E,et al. The evaluation of saphenofemoral insufficiency in primary adult varicocele. $\mathrm{J}$ Androl. 2011; 32(2):151-54.

[9]Ciaccio V, Ficola F, Ceccarelli F, Capodicasa E. Assessment of saphenofemoral junction continence in 42 patients with primary varicocele. Minerva Chir. 1995; 50(5):469-73.

[10] Karadeniz-Bilgili MY, Basar H, Simsir I, Unal B, Batislam E. Assessment of sapheno-femoral junction continence in patients with primary adolescent varicocoele. Pediatr Radiol. 2003; 33(9):603-6.

[11] Yetkin E, Kilic S, Acikgoz N, Ergin H, Aksoy Y, Sincer I,et al. Increased prevalence of varicocele in patients with coronary artery ectasia. Coron Artery Dis. 2005; 16(5):261-64.
[12]Kiliç S, Aksoy Y, Sincer I, Oğuz F, Erdil N, Yetkin E. Cardiovascular evaluation of young patients with varicocele. Fertil Steril. 2007; 88(2):369-73.

[13]Zabel M, Klingenheben T, Franz MR, Hohnloser SH. Assessment of QT dispersion for prediction of mortality or arrhythmic events after myocardial infarction: results of a prospective, longterm follow-up study. Circulation. 1998; 97(25):2543-50.

[14]Kors JA, Ritsema van Eck HJ, van Herpen G. The meaning of the Tp-Te interval and its diagnostic value. J Electrocardiol. 2008; 41(6):575-80.

[15]Perez MV, Dewey FE, Marcus R, Ashley EA, Al-Ahmad AA, Wang PJ,et al. Electrocardiographic predictors of atrial fibrillation. Am Heart J. 2009; 158(4):62228.

[16] Mihmanli I, Kurugoglu S, Cantasdemir M, Zulfikar Z, Halit Yilmaz M, Numan F. Color Doppler ultrasound in subclinical varicocele: an attempt to determine new criteria. Eur J Ultrasound. 2000; 12(1):4348.

[17] Bazett HC. An analysis of the time relations of electrocardiograms. Heart. 1920; 7: 353370

[18]Castro Hevia J, Antzelevitch C, Tornés Bárzaga F, Dorantes Sánchez M, Dorticós Balea F, Zayas Molina R, et al. Tpeak-Tend and Tpeak-Tend dispersion as risk factors for ventricular tachycardia/ventricular fibrillation in patients with the Brugada syndrome. J Am Coll Cardiol. 2006;47(9):1828-34.

[19]Serra R, Buffone G, Costanzo G, Montemurro R, Perri P, Damiano R, et al. Varicocele in younger as risk factor for inguinal hernia and for chronic venous disease in older: preliminary results of a 
prospective cohort study. Ann Vasc Surg. 2013;27(3):329-31.

[20]Turhan H, Erbay AR, Yasar AS, Balci M, Bicer A, Yetkin E. Comparison of Creactive protein levels in patients with coronary artery ectasia versus patients with obstructive coronary artery disease. Am J Cardiol. 2004;94(10):1303-6.

[21] Tousoulis D, Kampoli AM, Tentolouris C, Papageorgiou N, Stefanadis C. The role of nitric oxide on endothelial function. Curr Vasc Pharmacol. 2012;10(1):4-18.

[22]Zeinali M, Hadian Amree A, Khorramdelazad H, Karami H, Abedinzadeh M. Inflammatory and antiinflammatory cytokines in the seminal plasma of infertile men suffering from varicocele. Andrologia. 2017;49(6):1-4.

[23] Court O, Kumar A, Parrillo JE, Kumar A. Clinical review: Myocardial depression in sepsis and septic shock. Crit Care. 2002;6(6):500-8.

[24] de Bruyne MC, Hoes AW, Kors JA, Hofman A, van Bemmel JH, Grobbee DE. QTc dispersion predicts cardiac mortality in the elderly: the Rotterdam Study. Circulation. 1998;97(5):467-72.

[25] Somberg JC, Molnar J. Usefulness of QT dispersion as an electrocardiographically derived index. Am J Cardiol. 2002;89(3):291-94.

[26] Haarmark C, Hansen PR, Vedel-Larsen E, Pedersen SH, Graff C, Andersen MP, et al. The prognostic value of the Tpeak-Tend interval in patients undergoing primary percutaneous coronary intervention for STsegment elevation myocardial infarction. J Electrocardiol. 2009;42(6):555-60.

[27] Gialafos JE, Dilaveris PE, Gialafos EJ, George KA, Dimitrios JR, Filippos T, et al. $P$ wave dispersion: A valuable electrocardiographic marker for the prediction of paroxysmal lone atrial fibrillation. Ann Noninvasive Electrocardiol.1999; 4(1): 39-45.

[28] Gökçe M, Görenek B. P Wave Dispersion. Turkish Journal of Arrhythmia, Pacing and Electrophysiology. 2003; 3: 136-43. 